\title{
Coalesced Martensite in Pressure Vessel Steels
}

\author{
Hector Pous-Romero* \\ Department of Materials Science \& Metallurgy \\ University of Cambridge \\ Cambridge, Cambridgeshire CB2 3QZ \\ United Kingdom \\ Email: hp323@cam.ac.uk \\ Harry Bhadeshia \\ Department of Materials Science \& Metallurgy \\ University of Cambridge \\ Cambridge, Cambridgeshire CB2 3QZ \\ United Kingdom \\ Email: hkdb@cam.ac.uk
}

An alloy commonly used for large pressure vessels, known as SA508 Gr.3, has a microstructure after heat treatment consisting of a mixture of tempered bainite and martensite at fast cooled regions near surfaces subject to water quenching. These two phases are conventionally recognised to consist of fine platelets, each of which is approximately $0.2 \mu \mathrm{m}$ in thickness; enhancing strength and leading to good toughness properties.

We have discovered in our experimental work that there are circumstances where the adjacent platelets of a similar orientation can coalesce as the austenite transforms, to produce much coarser structures which are believed to be detrimental to toughness. An examination of published micrographs reveals that such coalesced regions existed but were not noticed in previous studies. The mechanism of coalescence is described and methods to ameliorate the coarsening are discussed.

\section{Nomenclature}

RPV Reactor pressure vessels.

SEM Scanning electron microscopy.

HAZ Heat affected zone.

$\mathrm{B}_{s} \quad$ Bainite start transformation temperature.

$\mathrm{M}_{s}$ Martensite start transformation temperature.

\section{Introduction}

An alloy used in the manufacture of RPV, designated commercially as SA508 Grade 3, has a typical chemical

\footnotetext{
${ }^{*}$ Corresponding author.
}

composition:

$$
\mathrm{Fe}-0.2 \mathrm{C}-1.3 \mathrm{Mn}-0.9 \mathrm{Ni}-0.5 \mathrm{Mo}-0.2 \mathrm{Cr}-0.2 \mathrm{Si} \mathrm{wt} \% \text {. }
$$

The components made using this material can be very large, wall thickness usually varies between 200 and $700 \mathrm{~mm}[1,2]$. It follows that the cooling rate must vary significantly as a function of depth from the surface. As a result, the microstructure generated can range from allotriomorphic ferrite in regions where the rate is slowest, to bainite or martensite where it is sufficiently rapid. The latter microstructures are desired since the steel is severely tempered, typically at $640^{\circ} \mathrm{C}$ for many hours. The martensitic or bainitic regions remain relatively fine during this process and hence ensure the required level of toughness. The precipitation of carbides such as the molybdenum rich $\mathrm{M}_{2} \mathrm{C}$ needles (' $\mathrm{M}$ ' stands for metal atoms) also tends to be more uniform in regions where the initial microstructure obtained on cooling is itself fine, i.e., the products of displacive transformation.

However, during the course of our investigations, some extremely coarse plates of martensite were observed, which according to recent theory, result from the coalescence of, separately nucleated, adjacent laths [3-6]. Such coalesced martensite is known in other contexts to be detrimental to toughness, since each of the coarse plates is essentially crystallographically homogeneous and hence offers little resistance to cleavage crack propagation $[3,7,8]$. Previous studies have suggested that the process of coalescence is favoured by large undercooling below the equilibrium transformation temperature and that large austenite grain sizes must assist the process of coalescence [3]. However, it remains the case that experimental verification of the ideas 
is still minimal.

Therefore the purpose of the present work is to systematically study the effects of cooling rate and austenite grain size on the formation of coalesced structures, and to report the first observations of coalesced martensite in SA508 Gr. 3, with the aim of understanding the structure and helping to mitigate its consequences in an otherwise fine dispersion of martensite laths.

Findings made in the present study, leading to a possible reduction in toughness due to the existence of coalesced martensite, refer to the as prior service condition. Since SA508 steels are susceptible to neutron irradiation embrittlement during operation, this will also result in a loss of toughness [9-11].

\section{Mechanism of Coalescence}

It has been discovered that there are circumstances where adjacent platelets of bainite or martensite that share the same habit plane and variant of the orientation relationship with austenite tend to impinge and coalesce in the absence of intervening phases to form much coarser structures [3-5]. These coarser structures, referred to as coalesced bainite or martensite, form during the course of phase transformation by the merger of finer plates, each of which is separately nucleated but in the same crystallographic orientation during prolonged growth $[3,4]$. This creates a strong bimodal size distribution of plates, where coarser structures of several micrometers thick are surrounded by much finer plates, as seen in Fig. 1

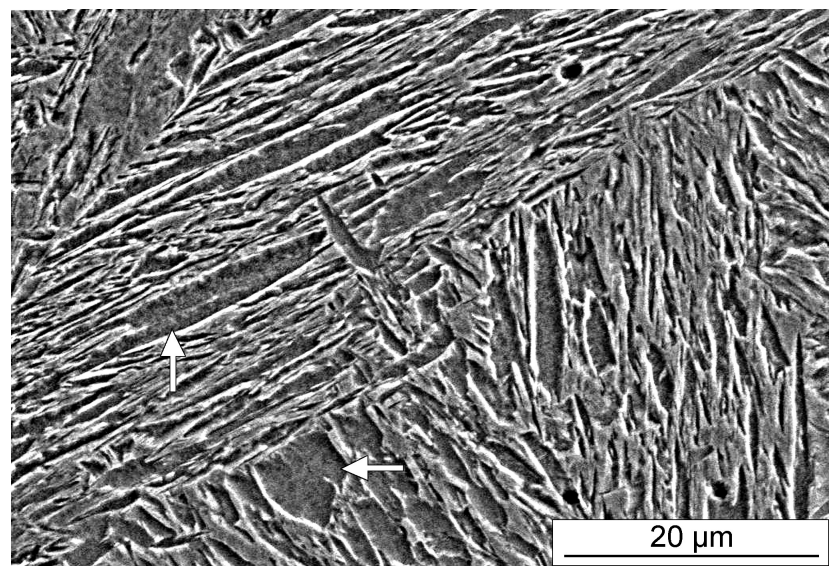

Fig. 1. SEM of the SA508 Gr. 3 studied in this work showing clear bimodal size distribution of martensitic plates. Sample austenitised at $1200^{\circ} \mathrm{C}$ for $48 \mathrm{~h}$ and water quenched. The arrows indicate regions where structures have coalesced.

The coalescence of martensitic structures has hardly been reported when compared to bainite for which there is a firm theoretical framework $[3,5,12]$. It is quite recent that
Table 1. Chemical composition of as-received SA508 Gr. 3 steel (wt\%).

\begin{tabular}{cccccc}
\hline $\mathrm{C}$ & $\mathrm{Mn}$ & $\mathrm{Ni}$ & $\mathrm{Mo}$ & $\mathrm{Cr}$ & $\mathrm{Si}$ \\
\hline 0.17 & 1.315 & 0.785 & 0.53 & 0.27 & 0.22 \\
$\mathrm{Co}$ & $\mathrm{Al}$ & $\mathrm{Nb}$ & $\mathrm{Ti}$ & $\mathrm{Sb}$ & $\mathrm{As}$ \\
\hline 0.01 & 0.0145 & 0.004 & 0.002 & 0.002 & 0.005 \\
$\mathrm{Cu}$ & $\mathrm{P}$ & $\mathrm{S}$ & $\mathrm{Sn}$ & $\mathrm{N}$ & $\mathrm{H}$ \\
\hline 0.04 & 0.004 & 0.002 & 0.006 & 0.007 & $0.65(\mathrm{ppm})$ \\
\hline
\end{tabular}

attempts have been made to explain the formation of coalesced martensite [13]. Fat plates are associated with large strain energies since the latter scales with the thickness to length ratio [14]; the driving force for transformation must be greater than this strain energy for the coalescence to occur. It has been demonstrated, for example, that supplementing the chemical driving force by a mechanical component due to applied stress, increases the propensity for martensite plates to combine [13]. Stress-affected transformations can cause major plate alignment with as little as $40 \mathrm{MPa}$, while stresses of $50 \mathrm{MPa}$ have shown to increase significantly the formation of coalesced structures $[15,16]$. Stresses of this level are quite feasible during the heterogeneous cooling of large components, such as RPV, due to thermal contractions.

\section{Experimental Procedure}

The chemical composition of the SA508 Gr. 3 steel used in this work is given in Table 1. The material in its as-received state had been subjected to multiple heat treatments: austenitisation between 860 and $880^{\circ} \mathrm{C}$ for approximately $12 \mathrm{~h}$, water quenched and tempered between 635 and $655^{\circ} \mathrm{C}$ for $10 \mathrm{~h}$. The range in temperatures is due to the thermal gradients in thick samples, which makes the temperature in a particular location uncertain.

Specimens from the as-received condition were reheated at three different austenitising conditions; $860^{\circ} \mathrm{C}$ for $1 \mathrm{~h}$, $1150{ }^{\circ} \mathrm{C}$ for $10 \mathrm{~min}$ and $1200^{\circ} \mathrm{C}$ for $48 \mathrm{~h}$. Austenitisation conditions were chosen based on a previous work of the authors [17], to obtain very dissimilar grain growth kinetics to understand the effects of austenite grain size on the formation of coalesced martensite. Following austenitisation, samples were continuously cooled to obtain martensite at cooling rates from 4 to $665^{\circ} \mathrm{Cs}^{-1}$. Dilatometric analyses were performed in samples cooled up to $40^{\circ} \mathrm{C} \mathrm{s}^{-1}$, and transformation temperatures were measured by the offset method [18]. For cooling rates above $40{ }^{\circ} \mathrm{C} \mathrm{s}^{-1}$ samples were water cooled with temperature monitored at the surface. Austenite grain sizes for the austenitising conditions described above were revealed by thermal etching and characterised by the linear 
Table 2. Measured austenite grain sizes for the different austenitising conditions

\begin{tabular}{cc}
\hline Austenitising condition & Grain size $/ \mu \mathrm{m}$ \\
\hline $860^{\circ} \mathrm{C}$ for $1 \mathrm{~h}$ & $7 \pm 0.5$ \\
$1150^{\circ} \mathrm{C}$ for $10 \mathrm{~min}$ & $126 \pm 9.8$ \\
$1200^{\circ} \mathrm{C}$ for $48 \mathrm{~h}$ & $221 \pm 18.7$ \\
\hline
\end{tabular}

intercept method with data obtained from four different fields of the sample and a total of 72 linear intercept lines. For SEM assessments the specimens were etched using $2 \%$ nital etchant. Each heat treated sample was used once and retained for standard metallographic and Vickers hardness tests. Calculated $B_{S}$ and $M_{S}$ temperatures have been obtained using the MUCG83 software, which predicts isothermal transformation diagrams, from the chemical composition of the steel [19], being 546 and $405^{\circ} \mathrm{C}$ respectively.

\section{Results and Analysis}

Thermal etching was found to be a suitable technique to reveal austenite grain boundaries in SA508 Gr. 3, as this technique allows for a clear delimitation of grain boundaries due to the formation of thermal grooves, as seen in Fig. 2. Table 2 summarises the measured austenite grain sizes for the different austenitising conditions. The large difference in austenite grain sizes was intentionally engineered to gain an understanding of the consequence of grain size on the formation of coalesced martensite in SA508 Gr. 3 steels.

\subsection{Determining martensitic transformation}

Dilatometric experiments have been carried out to determine the extent of bainitic or martensitic transformation after quenching at different cooling rates. The dilatometric curves during continuous cooling from 4 to $30^{\circ} \mathrm{C} \mathrm{s}^{-1}$ are presented in Fig. 3. By comparing the experimental transformation temperature with the calculated using MUCG83, it can be seen that at cooling rates of $4{ }^{\circ} \mathrm{C} \mathrm{s}^{-1}$ the transformation is fully bainitic, while at cooling rates of $10^{\circ} \mathrm{C} \mathrm{s}^{-1}$ and above the material becomes fully martensitic. At intermediate cooling rates, $7^{\circ} \mathrm{C} \mathrm{s}^{-1}$, the final microstructure at room temperature is a mixture of bainite and martensite. Bainite starts to form below $499 \pm 12^{\circ} \mathrm{C}$ during cooling at $4^{\circ} \mathrm{C} \mathrm{s}^{-1}$. As the martensitic transformation is expected to be athermal, the $M_{S}$ temperature should be independent of the cooling rate. Therefore, the $M_{S}$ temperature was considered as the averaged value of transformation temperatures for cooling rates of $10^{\circ} \mathrm{C} \mathrm{s}^{-1}$ and above, resulting in a measured transformation temperature of $368 \pm 8^{\circ} \mathrm{C}$. This work will concentrate on the analysis of fully martensitic structures formed at cooling rates of $10^{\circ} \mathrm{C} \mathrm{s}^{-1}$ and above.
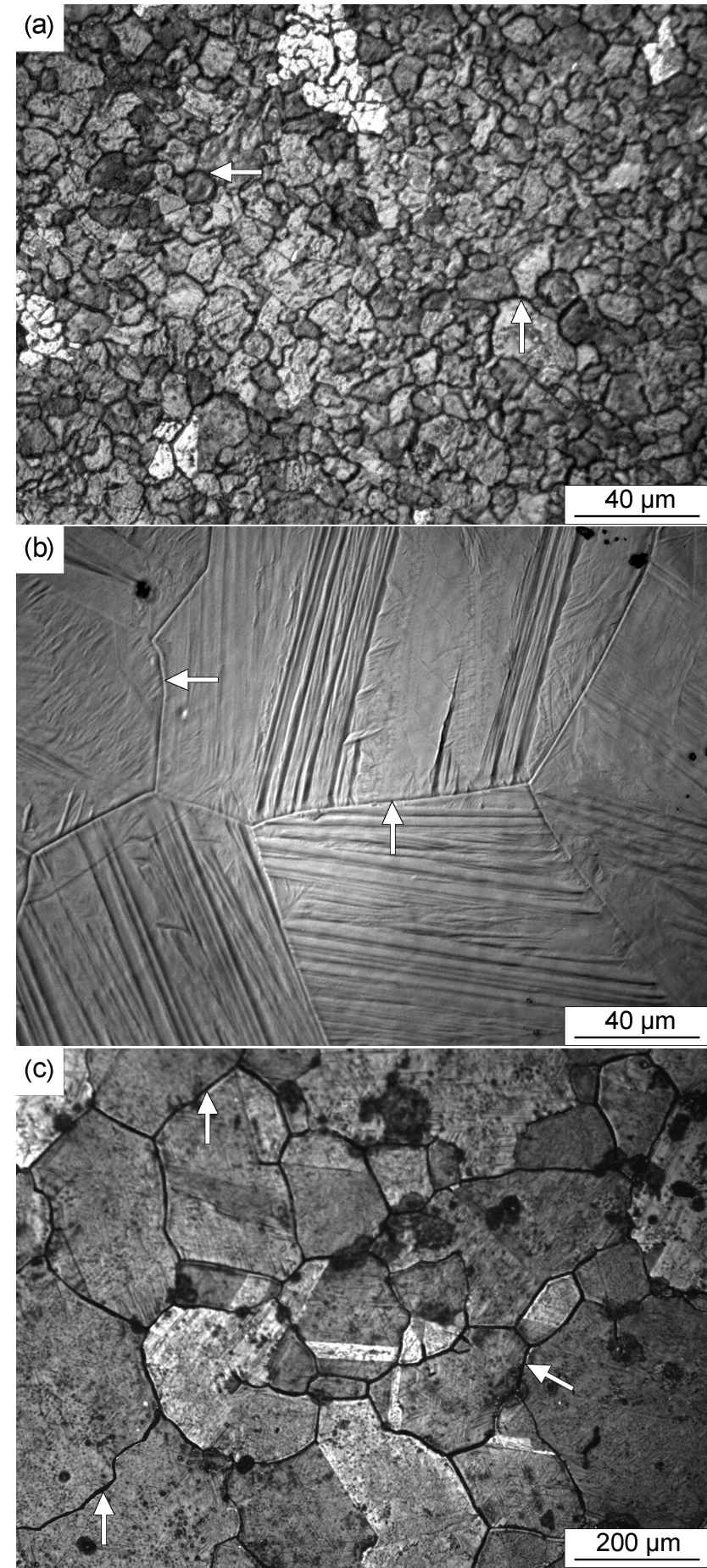

Fig. 2. Austenite grain size revealed by thermal etching. A) Austenitised at $860^{\circ} \mathrm{C}$ for $1 \mathrm{~h}$. B) Austenitised at $1150^{\circ} \mathrm{C}$ for $10 \mathrm{~min}$. C) Austenitised at $1200{ }^{\circ} \mathrm{C}$ for $48 \mathrm{~h}$. Arrows point at thermal grooves defining austenite grain boundaries.

\subsection{Identification of Coalesced Martensite in SA508 Steel}

The significance of coalesced structures of bainite and marteniste, was recognised first by Chang and Bhadeshia [12]. However, an examination of the literature shows that the structures have appeared in other publications but have not been recognised as such, even for pressure 


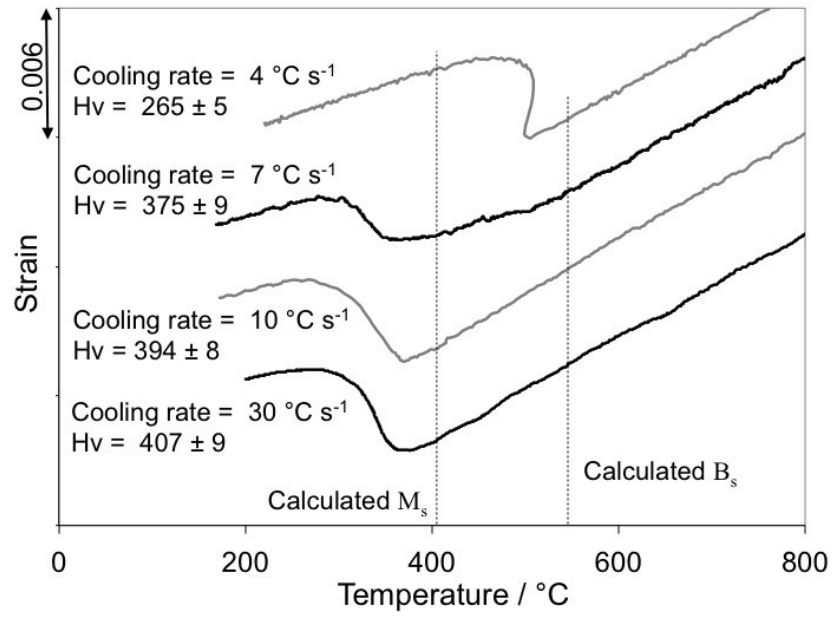

Fig. 3. Dilatometric curves after austenitisation at $1150{ }^{\circ} \mathrm{C}$ for $10 \mathrm{~min}$, Showing the transformation behaviour during continuous cooling at $4,7,10$ and $30^{\circ} \mathrm{Cs}^{-1}$. Hardness Vickers $(\mathrm{Hv})$ values also shown.

vessels steels [20-23].

Figure 4 shows the martensite obtained after austenitising at $1150{ }^{\circ} \mathrm{C}$ for $10 \mathrm{~min}$, where abnormally large martensitic structures can be differentiated from an otherwise fine dispersion of martensite platelets. Figure $4 \mathrm{c}$ shows that the coalesced plates of martensite retain vestiges of their origins from individual platelets, which are the boundaries between the individual units which participated in the coalescence. This proves that the gross structure was formed by the merging of smaller plates, not the coarsening of a single plate in isolation.

Comparing the data for different cooling rates, there is evidence that changing from 10 to $40^{\circ} \mathrm{C} \mathrm{s}^{-1}$, does not increase the likelihood of finding coalesced structures or their size, when the austenite grain size is maintained, as coalesced plates with a length $\sim 20 \mu \mathrm{m}$ and thickness $\sim 3 \mu \mathrm{m}$ have been found regardless of the cooling rate. This agrees with the fact that the mechanism of coalescence is controlled by the driving force during transformation, and therefore, the transformation temperature [13]. Figure 5 shows the calculated relationship between transformation temperature and driving force.

Analysis of the formation of coalesced martensite reveals that the coarse structures form independently of the austenite grain size over the range examined. Figure 6 shows the resultant martensitic microstructure after water quenching $\left(80^{\circ} \mathrm{C} \mathrm{s}^{-1}\right)$ of SA508 Gr. 3 steel after austenitisation at $860^{\circ} \mathrm{C}$ for $1 \mathrm{~h}$ and at $1200{ }^{\circ} \mathrm{C}$ for $48 \mathrm{~h}$. Experimental results show a clear relationship between austenite grain size and the dimensions, specially the length, of coalesced plates, as suggested by Bhadeshia [3]. As the austenite grain size is reduced from 221 to $7 \mu \mathrm{m}$, the length of the coarse structures is reduced, from $\sim 45 \mu \mathrm{m}$ to $\sim 7 \mu \mathrm{m}$, while the thickness remains similar for both cases at $\sim 3 \mu \mathrm{m}$ (these are apparent values since they have not been assessed for sectioning ef-
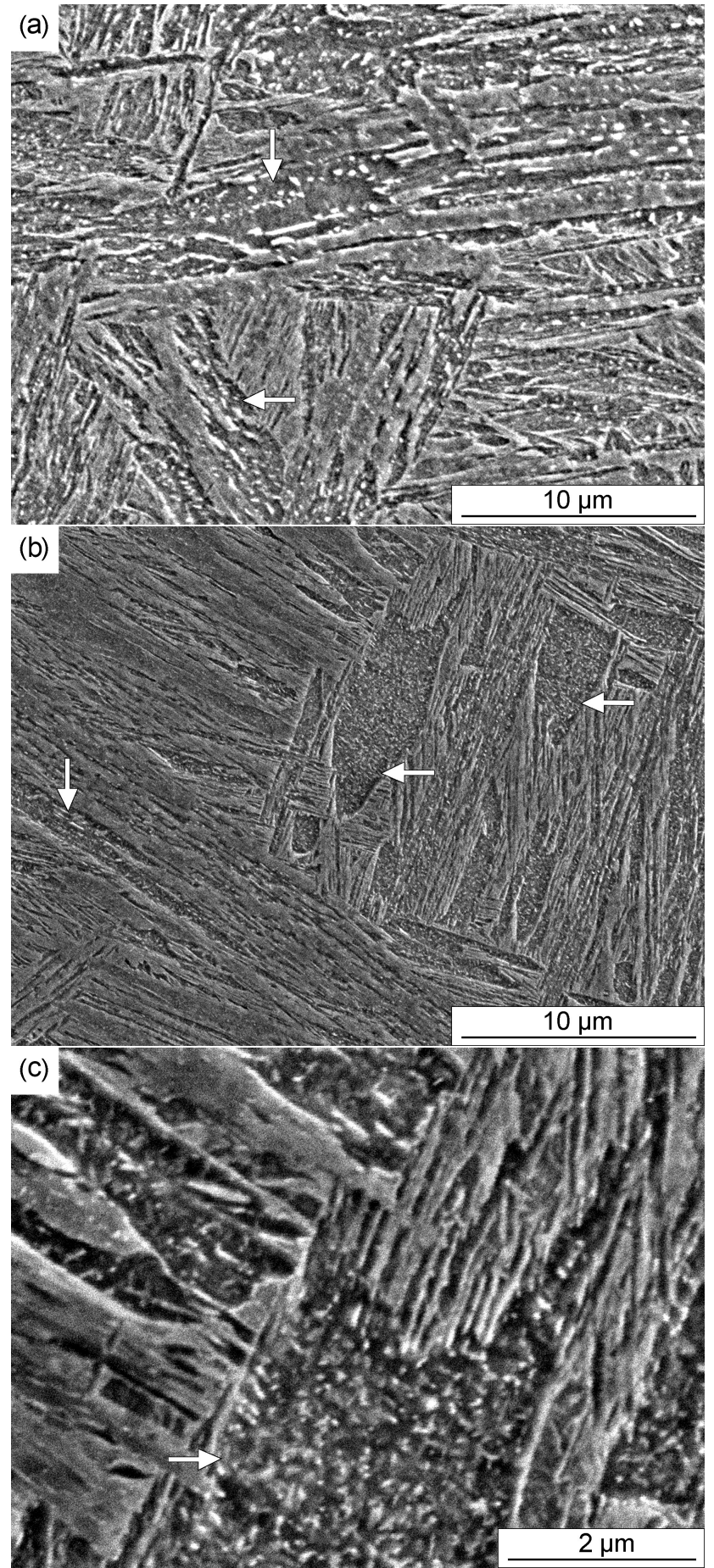

Fig. 4. SEM micrographs of SA508 Gr.3 steel austenitised at $1150^{\circ} \mathrm{C}$ for $10 \mathrm{~min}$ showing coalesced martensite. A) Cooled at $10^{\circ} \mathrm{Cs}^{-1}$. B) Cooled at $30^{\circ} \mathrm{Cs}^{-1}$. C) High magnification image of Fig. B showing serrated edges.

fects).

Therefore the propensity to form coalesced martensite in SA508 Gr. 3 steel is insensitive to the austenite grain size, at cooling rates where fully martensitic microstructures are formed. 


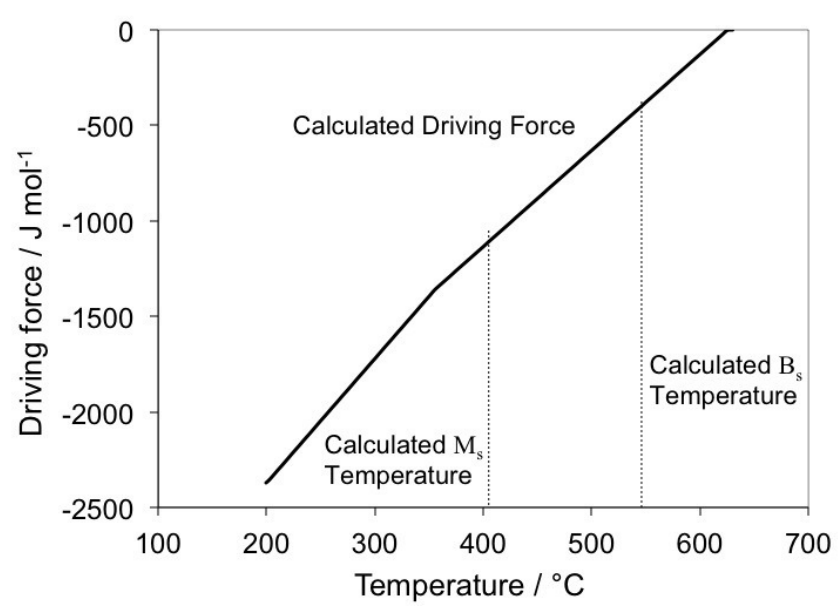

Fig. 5. Calculated driving force versus transformation temperature for SA508 Gr. 3 steel calculated using MUCG83.
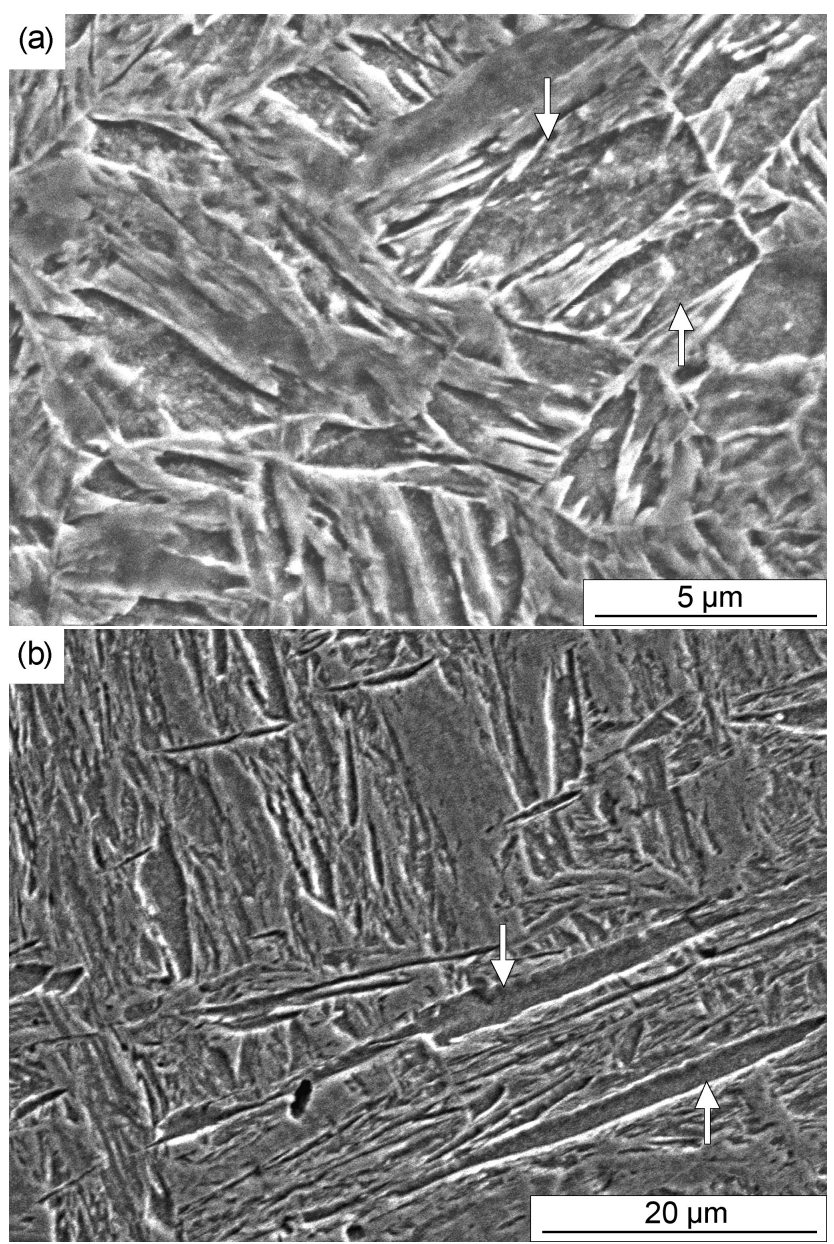

Fig. 6. Size differences in coalesced martensite plates for different austenitic grain sizes. A) Austenitised at $860^{\circ} \mathrm{C}$ for $1 \mathrm{~h}$. B) Austenitised at $1200^{\circ} \mathrm{C}$ for $48 \mathrm{~h}$.

\subsection{Effects on toughness}

A totally independent study on the toughness of heat affected zones of SA508 Gr. 3 steels, reported the case of a very low value of upper shelf energy Charpy impact energy, $67 \mathrm{~J}$, while normal values were in the order of $170 \mathrm{~J}$ [22]. The authors identified the structure as a coarse grained martensitic structure. However, there was no explanation given for the observed low value of impact energy. The lack of crack surface investigation from the authors in the cited article, makes it difficult to determine the specific reasons for the low value of Charpy impact energy. Nevertheless, after the findings made in the present work, it is clear by looking at the microstructure corresponding to the sample of low impact energy $(67 \mathrm{~J})$ that the reason of such low toughness may be related to the existence of coalesced martensite, Fig. 7. Although coarser structures are associated with lower toughness, it is noted that even the $67 \mathrm{~J}$ value must contain substantial ductile fracture. Further studies to conduct systematic experiments where both ductile and cleavage fracture are related to the presence or absence of coalesced martensite are recommended.

According to the experimental results obtained in the present investigation, by reducing the austenitic grain size, the dimensions of the coalesced martensite plates are considerably reduced. It is therefore tentatively proposed that to reduce the detrimental effect that coalesced martensite has on toughness, the austenite grain size should be maintained to a minimum by austenitising at temperatures below the grain "coarsening temperature", where grain boundaries experience a pinning force due to AlN precipitates so that the grain size rapidly reaches a limiting value [17]. To confirm the effects of the size of coalesced martensite on toughness in SA508 Gr. 3 steels more testing would be needed.

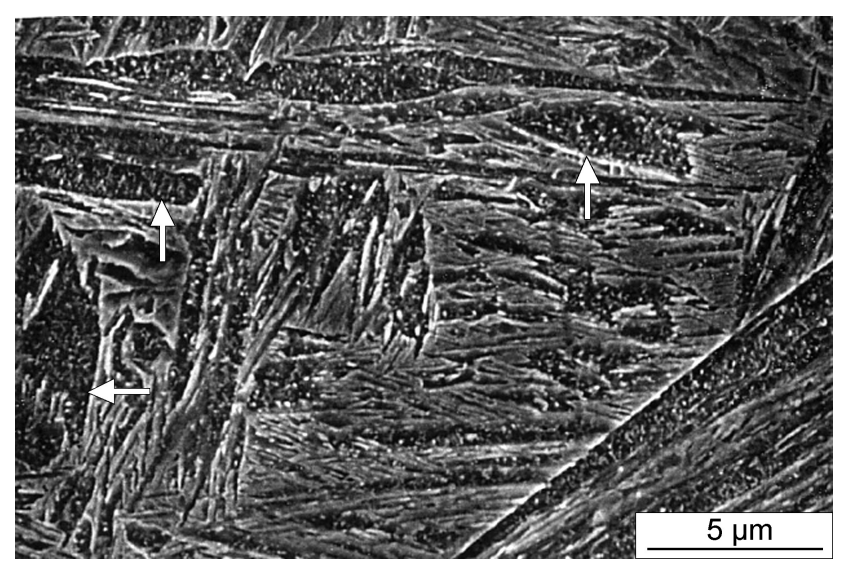

Fig. 7. Unnoticed case of coalesced martensite in the HAZ of a SA508 Gr. 3 steel, resulting in an unexplained very low value of impact energy [22].

\subsection{Tempering of coalesced structures}

It has been shown that coalesced martensite will form in rapidly cooled regions of the SA508 Gr. 3 forgings. However, ASME / ASTM specifications stipulate that a tempering treatment should be performed, over $620^{\circ} \mathrm{C}$ for $30 \mathrm{~min}$ or more per $25.4 \mathrm{~mm}$ of section thickness, following water quenching [24]. Therefore, it is important to 
understand the effects of this severe tempering on the coarse structures.

A sample austenitised at $1150^{\circ} \mathrm{C}$ for $10 \mathrm{~min}$ and icesalty-water quenched (the measured cooling rate at the surface was $665^{\circ} \mathrm{C} \mathrm{s}^{-1}$ ) was tempered at $660^{\circ} \mathrm{C}$ for $6.2 \mathrm{~h}$. Scanning electron microscopy confirmed the presence of coarse structures following tempering, Fig. 8. The larger carbides tended to decorate the plate boundaries, thus revealing the coarse scale of some of the tempered coalesced-martensite. The results show that the large coalesced martensite plates are retained in the tempered microstructure.

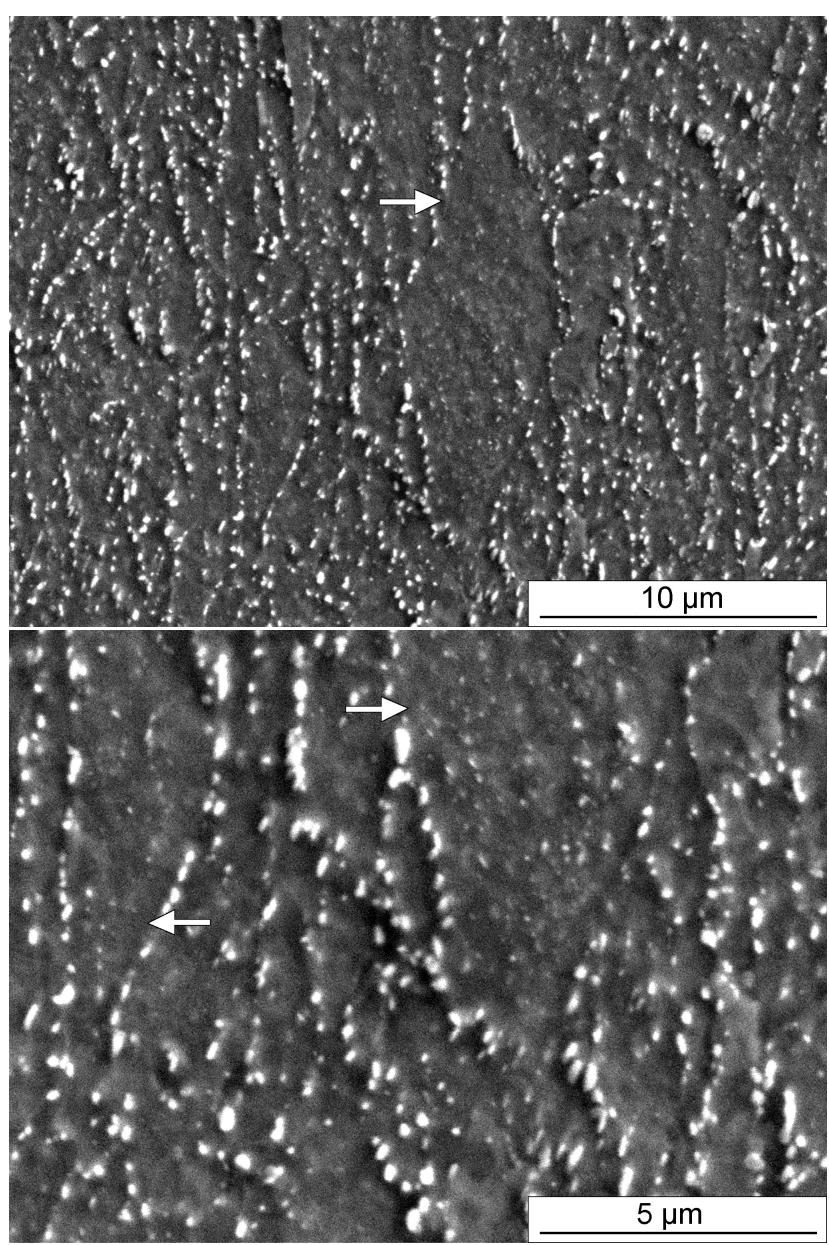

Fig. 8. SEM micrographs of SA508 Gr.3 steel austenitised at $1150{ }^{\circ} \mathrm{C}$ for $10 \mathrm{~min}$ showing coalesced martensite after tempering.

\section{Conclusions}

Coarse plates of martensite have been discovered in a nuclear pressure vessel steel (SA508 Gr. 3). These plates could lead to a deterioration in toughness given that they would be more effective at initiating cleavage failure and less effective in deflecting the propagation of cleavage cracks. The essential conclusions of the study relating the occurrence of coalesced plates as a function of the austenite grain size and cooling rate can be summarised as follows:

1. The coalescence of the martensite plates could not be avoided for cooling rates that exceed $10^{\circ} \mathrm{C} \mathrm{s}^{-1}$, where fully martensitic microstructures are formed. Indeed, the cooling rate over the range studied, did not seem to affect the number density or thickness of the coalesced structures.

2. A clear relationship between austenite grain size and the dimension of the coalesced structures is found. Smaller austenitic grains will result in a significant reduction in the length of the coalesced martensite plates.

3. Unexplained cases of very low toughness reported in previous studies of SA508 Gr. 3 steels may be explained by the presence of coalesced martensite in the microstructure. An examination of the published micrographs revealed coalesced martensite plates but their presence was not noted in the publications reviewed.

4. The merging of independently nucleated, adjacent platelets to produce thicker crystallographicallyhomogeneous grains must be detrimental to toughness. But the effect on toughness could be mitigated by minimising the austenite grain size, since this in turn limits the scale of the martensite.

5. Severe tempering does not destroy the bimodal platesize distribution resulting from the coalescence of some of the plates. The coalesced regions are clearly delineated by the precipitation of carbides at the boundaries of the coalesced plates.

6. The present work defines a need to relate toughness and fracture facet size to the underlying microstructure, and this forms the basis of our future work.

\section{Acknowledgements}

The authors are grateful to Rolls-Royce plc for sponsoring this work. Discussions with staff at Sheffield Forgemasters are also appreciated.

\section{References}

[1] Cogswell, D., Swan, D., Mitchell, R., and Garwood, S., 2010. "Materials and structureal integrity challenges for the next nuclear generation". In 63rd Annual Assembly and International Conference of the International Institute of Welding.

[2] Lee, B., Hong, J., Yang, W., Huh, M., and Chi, S., 2000. "Master curve characterization of the fracture toughness in unirradiated and irradiated RPV steels using full- and 1/3-size pre-cracked Charpy specimens". International Journal of Pressure Vessels and Piping, 77, pp. 599-604.

[3] Bhadeshia, H. K. D. H., Keehan, E., Karlsson, L., and Andrén, H. O., 2006. "Coalesced bainite". Transactions of the Indian Institute of Metals, 29, pp. 689-694.

[4] Pak, J. H., Bhadeshia, H. K. D. H., and Karlsson, L., 2012. "Mechanism of misorientation development 
within coalesced martensite". Materials Science and Technology, 28(8), pp. 918-923.

[5] Pak, J. H., Bhadeshia, H. K. D. H., Karlsson, L., and Keehan, E., 2008. "Coalesced bainite by isothermal transformation of reheated weld metal". Science and Technology of Welding and joining, 13(7), pp. 593597.

[6] Caballero, F. G., Chao, J., Cornide, J., García-Mateo, C., Santofimia, M. J., and Capdevila, C., 2009. "Toughness deterioration in advanced high strength bainitic steels". Materials Science and Engineering A, 525, pp. 87-95.

[7] Keehan, E., Bhadeshia, H. K. D. H., and Thuvander, M., 2008. "Electron backscatter diffraction study of the coalesced bainite i high strength steel weld metals". Materials Science and Technology, 24(10), pp. 11831188.

[8] Keehan, E., Karlsson, L., and Andrén, H. O., 2006. “Influence of carbon, mandanese and nickel on microstructure and properties of strong steel weld metal. part 1 Effect of nickel content". Science and Technology of Welding and joining, 11(1), pp. 1-8.

[9] Suzuki, K., 1982. "Neutron irradiation embrittlement of ASME SA508 Cl. 1 steel". Journal of Nuclear Materials, 109, pp. 443-450.

[10] Park, S. G., Kim, M. C., Lee, B. S., and Wee, D. M., 2010. "Correlation of the thermodynamic calculation and the experimental observation of Ni-Mo-Cr low alloy steel changing Ni, Mo, and Cr contents". Journal of Nuclear Materials, 407, pp. 126-135.

[11] Hawthorne, J., 1985. "Composition influences and interactions in radiation sensitivity of reactor vessel steels". Nuclear Engineering and Design, 89, pp. 223232.

[12] Chang, L. C., and Bhadeshia, H. K. D. H., 1996. "Microstructure of lower bainite formaed at large undercooling below bainite start temperature". Materials Science and Technology, 12, pp. 233-236.

[13] Pak, J. H., 2012. "Coalesced bainite and martensite". $\mathrm{PhD}$ thesis, GIFT, POSTECH.

[14] Christian, J. W., 1958. "Accommodation strains in martensite formation, the use of the dilatation parameter". Acta Metallurgica, 6, pp. 377-379.

[15] Bhadeshia, H. K. D. H., David, S. A., Vitek, J. M., and Reed, R. W., 1991. "Stress induced transformation to bainite in Fe-Cr-Mo-C pressure vessel steel". Materials Science and Technology, 7, pp. 686-698.

[16] Pak, J., Suh, D. W., and Bhadeshia, H. K. D. H., 2012. "Promoting the coalescence of bainite platelets". Scripta Materalia, 66, pp. 951-953.

[17] Pous-Romero, H., Lonardelli, I., Cogswell, D., and Bhadeshia, H. K. D. H., 2013. "Austenite grain growth in a nuclear pressure vessel steel". Materials Science and Engineering A, 567, pp. 72-79.

[18] Yang, H. S., and Bhadeshia, H. K. D. H., 2007. "Uncertainties in dilatometric determination of martensite start temperature". Materials Science and Technology, 23(5), pp. 556-560.
[19] Peet, M., and Bhadeshia, H. K. D. H., 1982. Software for transformations in steels. http://www.msm.cam.ac.uk/map/steel/programs/mucg83.html.

[20] Kim, S., Kang, S. Y., Oh, S. J., Kwon, S., Lee, S., Kim, J. H., and Hong, J. H., 2000. "Correlation of the microstructure and fracture toughness of the heat-affected zones of an SA508 steel". Metallurgical and Materials Transactions A, 31A, pp. 1107-1119.

[21] Kim, S., Lee, S., IM, Y. R., H. C. Lee, S. J. K., and Hong, J. H., 2004. "Effects of alloying elements on fracture toughness in the transition temperature region of base metals and simulated heat-affected zones of Mn-Mo-Ni low alloy steels". Metallurgical and Materials Transactions, 35A, pp. 2027-2037.

[22] Kim, S., Im, Y., Lee, S., Lee, H., Oh, Y. J., and Hong, J. H., 2001. "Effects of alloying elements on mechanical and fracture properties of base metals and simulated HAZ of SA508 steels". Metallurgical and Materials Transactions A, 32A, pp. 903-911.

[23] Jang, H., Kim, J.-H., Jang, C., Lee, J. G., and Kim, T. S., 2013. "Low-cycle fatigue bahaviours of two heats of SA508 Gr.1a low alloy steel in $310^{\circ} \mathrm{c}$ ais deoxygenated water - Effects of dynamic strain aging and microstructures". Materials Science and Engineering A, 580, pp. 41-50.

[24] ASTM, 2004. Standard Specification for Quenched and Tempered Vacuum-treated Cabon and Alloy Steel Forgings for Pressure Vessel Components A508A/A548M. 